\title{
Analisis Penerapan Lean Manufacturing untuk Menghilangkan Pemborosan di Lini Produksi PT Adi Satria Abadi
}

\author{
Muhammad Shodiq Abdul Khannan ${ }^{1 *}$, Haryono ${ }^{2}$ \\ 1*) Fakultas Teknologi Industri, Program Studi Teknik Industri, \\ Universitas Pembangunan Nasional Veteran \\ Jl. Babarsari 2, Tambakbayan, Yogyakarta 55281 \\ shodiqeupnyk.ac.id \\ 2) Fakultas Teknik, Program Studi Teknik Industri, \\ Universitas Sarjanawiyata Tamansiswa \\ Jl. Kusumanegara 157, Yogyakarta 55165 \\ email : har.yono90eyahoo.com
}

\begin{abstract}
Productivity achievement at PT Adi Satria Abadi (Golf Gloves Division) is not optimal because of the waste. Value Stream Mapping as a Lean Manufacturing tool is used to map the production process and identify and eliminate the waste. The advantage of VSM is its capability to give visual map of value added flow process, necessary but non value added flow process, and non value added flow process. In this study Waste Assessment Model (WAM) also have been implemented to identify the waste. The sequence of three greatest waste are Defect/Reject 24,73\%, Unneccessary Inventory 18,80\%, and Unneccessary Motion 15,44\%. This study can reduce production lead time 62,22 minutes and improve the production throughput by 77 pcs.
\end{abstract}

Keywords: Lean manufacturing; Value Stream Mapping; Waste Assessment Model; and Production Throughput

\begin{abstract}
Abstrak
Pencapaian produktivitas perusahaan PT Adi Satria Abadi (Divisi Sarung Tangan Golf) kurang optimal disebabkan masih banyaknya pemborosan (waste). Metode Value Stream Mapping sebagai salah satu alat dalam Lean Manufacturing digunakan untuk memetakan proses produksi yang ada dan mengidentifikasi proses yang mengandung pemborosan sehingga pemborosan yang ada bisa dihilangkan. Keunggulan VSM yaitu dapat memvisualisasikan aliran proses Value Added (VA), Necessary but Non Value Added (NBNVA) dan Non Value Added (NVA). Pada penelitian ini Metode Waste Assessment Model (WAM) juga digunakan untuk mengidentifikasi pemborosan. Berdasarkan hasil analisis didapatkan tiga urutan terbesar pemborosan yaitu Defect/Reject 24,73\%, Unneccessary Inventory 18,80\%, dan Unneccessary Motion 15,44\%. Output dari penelitian ini adalah terjadinya penurunan lead time sebesar 62,22 menit serta peningkatan pada throughput produksi sebesar 77 pcs.

Kata Kunci: Lean manufacturing; Value Stream Mapping; Waste Assessment Model; dan throughput produksi
\end{abstract}

\section{Pendahuluan}

Ketatnya persaingan dalam dunia industri memacu perusahaan manufaktur untuk memiliki keunggulan kompetitif yaitu kualitas (qua-

${ }^{*}$ Korespondensi Penulis lity), harga (cost), ketepatan waktu pengiriman (delivery time), dan fleksibilitas (flexibility). PT Adi Satria Abadi merupakan perusahaan yang bergerak di bidang pembuatan sarung tangan golf di Kota Yogyakarta. Produk yang dihasilkan perusahaan terdiri atas berbagai merek 
dan varian serta produknya sudah memasuki pasar ekspor. Permasalahan yang terjadi di perusahaan adalah masih dijumpai banyaknya pemborosan (waste) dalam hal waktu produksi akibat adanya aktivitas yang tidak efisien atau tidak mempunyai nilai tambah (non value added). Aktivitas yang tidak mempunyai nilai tambah antara lain terdapat pada proses penyediaan bahan baku dari supplier, aliran bahan dari proses awal sampai proses akhir, pergerakan alat dan mesin yang tidak sesuai kapasitas, proses menunggu, dan proses pengerjaan ulang (rework). Metode yang terbukti sangat bagus dalam mengurangi waste adalah Lean Manufacturing. Lean manufacturing merupakan suatu pendekatan sistematis untuk mengidentifikasi dan mengeliminasi pemborosan (waste) melalui serangkaian aktivitas penyempurnaan (improvement) (Gaspersz, 2007).

Pemborosan atau waste, dalam bahasa Jepang disebut muda, merupakan segala sesuatu tindakan yang dilakukan tanpa menghasilkan nilai. Taiichi Ohno, seorang eksekutif Toyota, merupakan orang pertama yang mencetuskan tujuh macam pemborosan. Kemudian Linker menambahkan satu jenis pemborosan pada tujuh macam pemborosan tersebut (Daonil, 2012). Lean manufacturing adalah suatu pendekatan sistematis untuk mengidentifikasi dan mengeliminasi pemborosan berupa aktivitas yang tidak memberi nilai lebih (non-value added activities) melalui perbaikan secara terus menerus dengan mengizinkan aliran produk dengan sistem tarik (pull system) dari sudut pelanggan dengan tujuan kesempurnaan kepuasaan pelanggan (Fontana, 2011).

Beberapa penelitian terkait dengan penerapan konsep lean manufacturing antara lain : Daonil(2012) menggunakan metode Value Steam Mapping untuk menghilangkan pemborosan di perusahaan dying dan printing; Sandroto (2007) yang menggunakan metode Value Stream Mapping pada industri susu balita; Muzakki (2012) menerapkan lean manufacturing untuk mengeliminasi waste pada lini machining cast wheel; Pertiwi (2012) menggunakan konsep lean hospital untuk perbaikan sistem rack addresing dan order picking di sebuah rumah sakit; Chaeron (2014) mengimplementasikan konsep lean thinking di PT Adi Satria Abadi (divisi penyamakan kulit). Berbeda dengan penelitian-penelitian sebelumnya, penelitian dalam paper ini dilakukan di PT Adi Satria Abadi (divisi sarung tangan kulit) dan menganalisis implementasi lean manufacturing pada industri sarung tangan kulit.

\section{Tujuan}

Tujuan dari penelitian ini adalah sebagai berikut.

1. Mengidentifikasi dan mengurangi waste (pemborosan) yang menghambat produktivitas perusahaan PT Adi Satria Abadi.

2. Menghitung lead time produksi sebelum dan sesudah perbaikan.

3. Menghitung throughput proses produksi di PT Adi Satria Abadi sebelum dan sesudah dilakukan perbaikan.

\section{Metode Penelitian}

Tahapan penelitian bisa digambarkan dalam diagram alir seperti terlihat pada Gambar 1 .

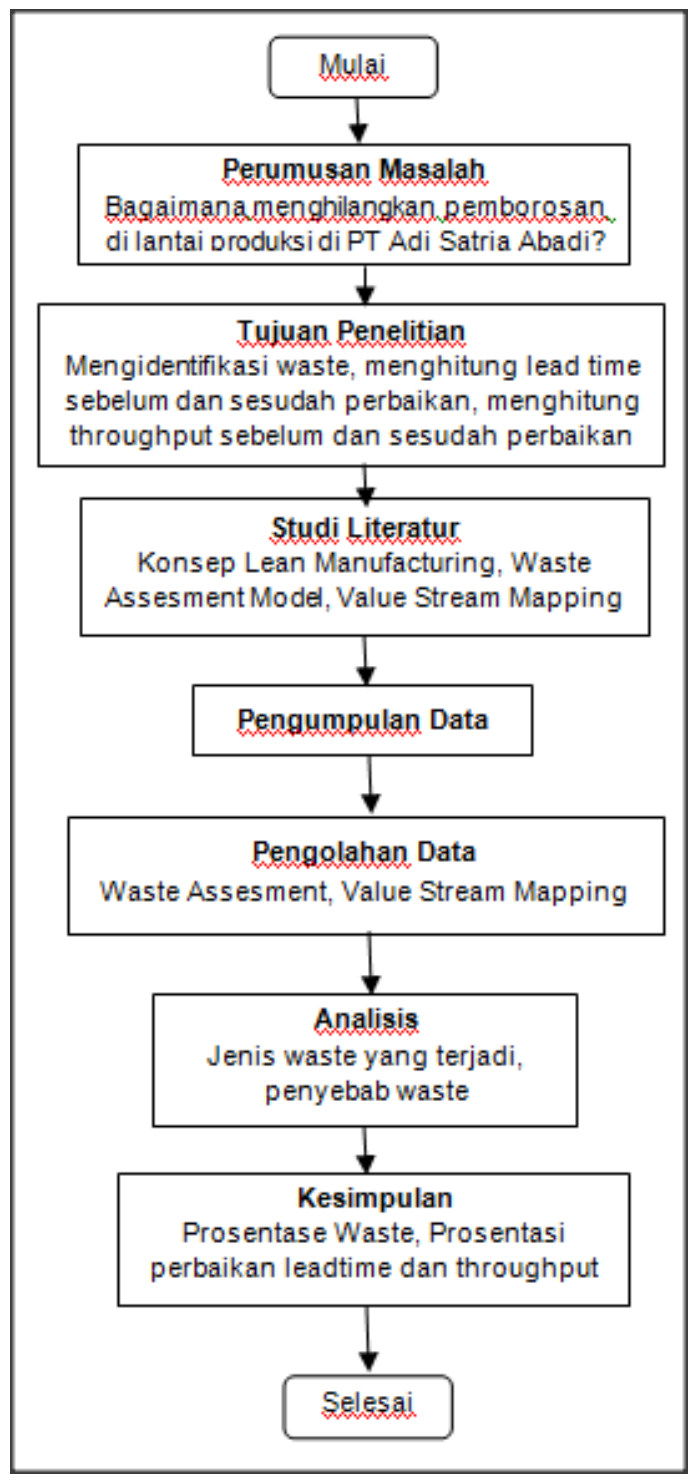

Gambar 1: Diagram alir penelitian 
Penelitian ini menggunakan Konsep Waste Assesment Model dalam mengidentifikasi waste yang ada di lantai produksi. Value Stream Mapping digunakan untuk memetakan aliran value dari awal sampai akhir proses untuk kondisi awal (current condition) dan kondisi masa depan (future condition) yang lebih baik.

\section{Konsep Waste Assesment Model}

Waste Assessment Model merupakan suatu model yang dikembangkan untuk menyederhanakan pencarian dari permasalahan waste dan mengidentifikasi untuk mengeliminasi waste (Rawabdeh, 2005). Model ini menggambarkan hubungan antar seven waste (O: Overproduction, P: Processing, I: Inventory, T: Transportation, D: Defects, W: Waiting, dan M: Motion).

2. Seven Waste Relationship

Semua jenis waste bersifat interdependent dan berpengaruh terhadap jenis lain. Tujuh waste dapat dikelompokkan ke dalam tiga kategori utama yang dikaitkan terhadap man, machine, dan material. Kategori man berisi konsep motion, waiting, dan overproduction. Kategori machine meliputi overproduction waste, sedangkan kategori material meliputi transportation, inventory, dan defect.

3. Waste Relationship Matrix (WRM)

Waste Relationship Matrix (WRM) merupakan matriks yang digunakan untuk menganalisis kriteria pengukuran.

4. Waste Assessment Questionnaire (WAQ) Waste Assesment Questionnaire dibuat untuk mengidentifikasi dan mengalokasikan waste yang terjadi pada lini produksi. Ada delapan tahapan perhitungan skor waste untuk mencapai hasil akhir berupa rangking dari waste, yaitu sebagai berikut.

A. Mengelompokkan dan menghitung jumlah pertanyaan kuesioner berdasarkan catatan "From" dan "To" untuk tiap jenis waste.

$B$. Memasukkan bobot dari tiap pertanyaan berdasarkan waste relationship matrix. Memperlihatkan contoh dari pemberian bobot awal berdasarkan WRM.

C. Menghilangkan efek dari variasi jumlah pertanyaan untuk tiap jenis pertanyaan dengan membagi tiap bobot dalam satu baris dengan jumlah pertanyaan yang dikelompokkan $\left(N_{i}\right)$.

$D$. Nilai pada tiap kolom waste dengan mengabaikan nilai nol.

$$
S_{j}=\sum_{k=1}^{k} \frac{W_{j} \cdot k}{N_{i}}
$$

$E$. Memasukkan nilai dari hasil kuisioner $(1,0,5$, atau 0$)$ ke dalam tiap bobot nilai di tabel dengan cara mengalikannya.

$F$. Menghitung total skor untuk tiap nilai bobot pada kolom waste dan frekuensi $\left(F_{j}\right)$ untuk nilai bobot pada kolom waste dengan mengabaikan nilai 0 (nol). Dengan persamaan:

$$
S_{j}=\sum_{k=1}^{k} X_{k} \times \frac{W_{j} \cdot k}{N_{i}}
$$

$G$. Di mana $s_{j}$ adalah total untuk nilai bobot waste, dan $X_{k}$ adalah nilai dari jawaban tiap pertanyaan kuesioner (1, $0,5$, atau 0$)$.

$H$. Menghitung indikator awal untuk tiap waste $\left(Y_{j}\right)$.

$$
Y_{j}=\frac{s_{j}}{S_{j}} \times \frac{f_{j}}{F_{j}}
$$

I. Menghitung nilai final waste factor $\left(Y_{\text {jfinal }}\right)$ dengan memasukkan faktor probabilitas pengaruh antarjenis waste $\left(P_{j}\right)$ berdasarkan total "From" dan "To" pada WRM.

$$
Y_{j \text { final }}=Y_{j} \times P_{j}=\frac{s_{j}}{S_{j}} \times \frac{f_{j}}{F_{j}} \times P_{j}
$$

Value Stream Mapping (VSM)

Value stream mapping adalah sebuah metode visual untuk memetakan jalur produksi dari sebuah produk yang di dalamnya termasuk material dan informasi dari masing-masing stasiun kerja (Sandroto, 2007).

5. Kelebihan dan Kekurangan Value Stream Mapping

Kelebihan dan Kekurangan Value Stream yaitu cepat dan mudah dalam pembuatan, dalam pembuatannya tidak harus menggunakan software komputer khusus, mudah dipahami dan meningkatkan pemahaman terhadap sistem produksi yang sedang berjalan dan memberikan gambaran aliran perintah informasi produksi Fontana (2011). Setiap tools maupun metode memiliki beberapa kekurangan dalam penggunaannya. Kekurangan dari Value Stream Mapping adalah aliran material hanya bisa untuk satu produk atau satu tipe produk yang sama pada satu VSM untuk dianalisis dan VSM berbentuk statis dan terlalu menyederhanakan masalah yang ada pada lantai produksi. 


\section{Hasil dan Pembahasan}

Hasil dari tahap pengolahan data dapat disajikan dalam Tabel 1. Pada Tabel 1 terdapat perbandingan data sebelum dan sesudah perbaikan. Data pada Tabel 1 bisa digambarkan dalam bentuk grafik seperti pada Gambar 2 sampai dengan Gambar 6.

Tabel 1: Perbandingan Hasil Pada VSM Sebelum dan VSM Sesudah

\begin{tabular}{|l|c|c|c|}
\hline & VSM Sebelum & VSM Sesudah & Selisih \\
\hline $\begin{array}{l}\text { Waktu Siklus } \\
\text { Total }\end{array}$ & 11662 detik & 10987 detik & 675 detik \\
\hline $\begin{array}{l}\text { Total Waktu } \\
\text { Value Added }\end{array}$ & 59,067 menit & 59,067 menit & - \\
\hline $\begin{array}{l}\text { Total Waktu } \\
\text { Non Value } \\
\text { Added }\end{array}$ & 135,3 menit & 124,05 menit & 10,25 menit \\
\hline Lead Time & 602,25 menit & 540,03 menit & 62,22 menit \\
\hline WIP Time & 9,4610 jam & 8,7211 jam & 0,73 jam \\
\hline $\begin{array}{l}\text { Output pro- } \\
\text { duksi/hari }\end{array}$ & 1322 pcs & 1399 pcs & 77 pcs \\
\hline \multicolumn{4}{|l}{} \\
\hline \multicolumn{4}{|l}{} \\
\hline
\end{tabular}

\section{Perbandingan Lead Time}

Lead time raw material pada current value stream mapping dari waktu masuk proses pemotongan sampai produk jadi keluar dari proses pengepakan adalah 9 jam 21 menit sedangkan lead time pada propose value stream mapping adalah 9 jam 6 menit.

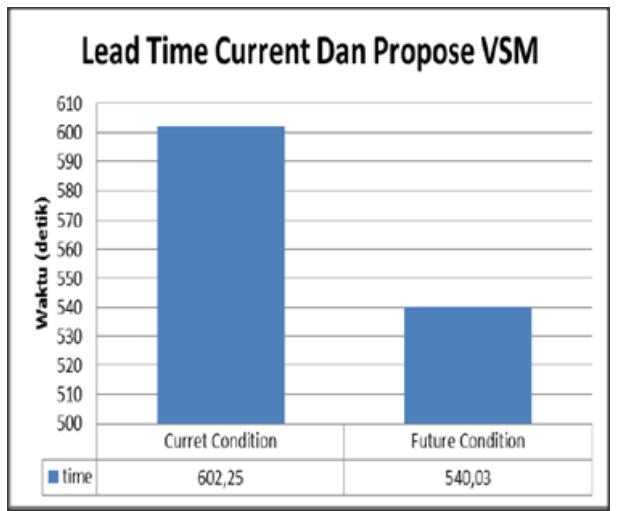

Gambar 2: Perbandingan lead time current dan propose VSM

Pada Future condition terdapat pengurangan waktu sekitar 62,22 menit, pengurangan waktu ini disebabkan karena ada perbaikan layout, pengaturan operator, serta mengurangi kegiatan nonvalue added.

2. Perbandingan Throughput Produksi

Throughput produksi dapat dilihat melalui perhitungan total waktu siklus current dan propose VSM. Waktu bekerja di perusahaan adalah selama 8 jam, dan terdapat pengurangan waktu istirahat, salat, dan makan selama 1 jam sehingga didapatkan net available time selama 420 menit atau 7 jam. Pada current value stream mapping dalam membuat produk 1322 pcs membutuhkan waktu 11662 detik, setelah dilakukan perbaikan menunjukkan hasil pada propose VSM total cyle time menjadi 10987 detik, sehingga terjadi penurunan throughput sebesar 675 detik. Oleh karena itu, waktu yang tersisa dalam perbaikan sebanyak 675 detik dapat menghasilkan 77 pcs, maka waktu keseluruhan yang dihasilkan setelah throughput sebanyak 1399 pcs. Peningkatan ini dapat meningkat disebabkan karena ada perbaikan pada stasiun kerja.

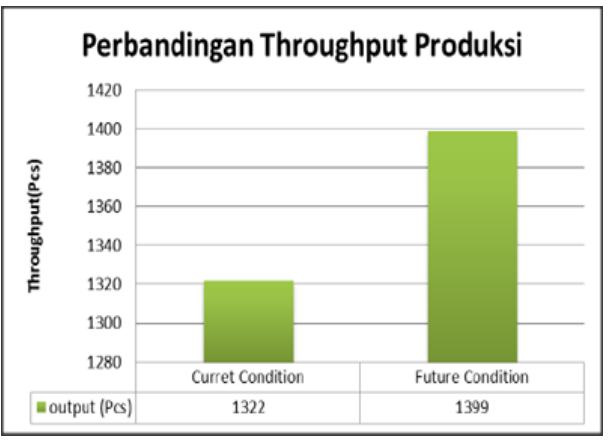

Gambar 3: Perbandingan throughput produksi current dan propose VSM

\section{Perbandingan WIP Current dan Propose VSM}

Pada current value stream mapping waktu WIP 9,4 jam sedangkan pada propose value stream mapping waktu WIP menurun menjadi 8,7 jam, terdapat penurunan WIP 0,7 jam atau 42 menit pada improvement yang sudah dilakukan. Berikut perbandingan WIP current condition dan after condition.

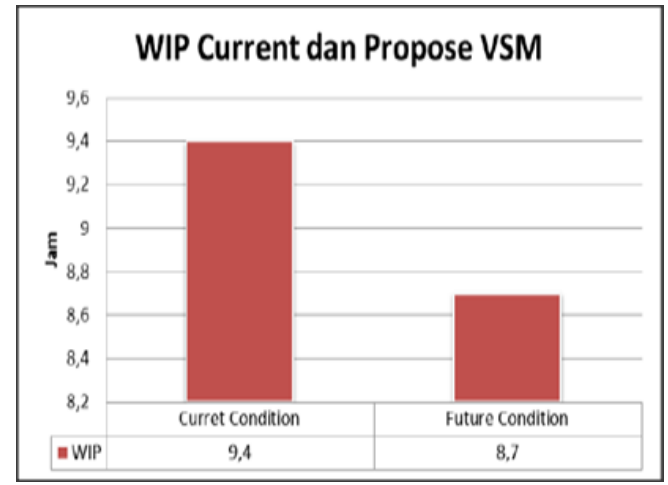

Gambar 4: WIP current dan propose VSM 


\section{Perbandingan NVA Current dan Propose VSM}

Pada current VSM terdapat aktivitas yang tidak memberi nilai tambah (non value added) sebesar 135,5 menit. Nonvalue added yang terjadi di lantai produksi cukup lama, sehingga setelah perbaikan waktu NVA pada sebesar 124,5 menit. Dengan terjadi penurunan sebesar 11 menit, maka aktivitas yang tidak menambah nilai tambah pada lantai produksi harus diminimalisasi lagi.

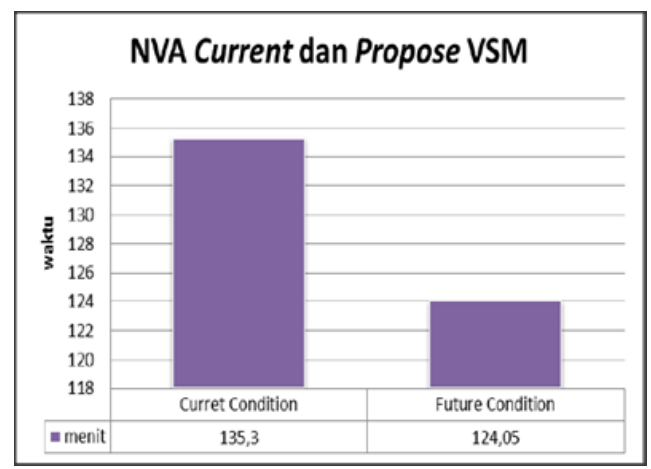

Gambar 5: NVA current dan propose VSM

\section{Analisis Hasil Identifikasi Waste}

Proses indentifikasi waste dilakukan dengan menggunakan metode Waste Assessment Model yang bertujuan untuk menyederhanakan pencarian permasalahan dan objektivitas penelitian. Keterlibatan lima responden yang kompeten dari setiap fungsi dan bertanggung jawab langsung terhadap operasional sistem dan proses produksi pada produk Callaway Fusion Pro $14 \mathrm{da}-$ pat dijadikan jaminan terhadap akurasi dan obyektivitas hasil assessmen. Hasil assessmen berupa peringkat waste secara berurutan dari yang terbesar sampai dengan yang terkecil dapat dilihat pada Tabel 2 berikut:

Tabel 2: Perbandingan Hasil Pada VSM Sebelum dan VSM Sesudah

\begin{tabular}{|c|c|c|c|}
\hline Peringkat & Jenis Waste & Presentase & $\begin{array}{c}\text { Akumulasi } \\
\text { Presentase }\end{array}$ \\
\hline 1 & Defet/Reject (D) & $24.73 \%$ & $24.73 \%$ \\
\hline 2 & $\begin{array}{c}\text { Unneccessary } \\
\text { Inventory (I) }\end{array}$ & $18.80 \%$ & $43.53 \%$ \\
\hline 3 & $\begin{array}{c}\text { Unneccessary Motion } \\
(\mathrm{M})\end{array}$ & $15.44 \%$ & $58.97 \%$ \\
\hline 4 & Waiting/Idle (W) & $13.42 \%$ & $72.39 \%$ \\
\hline 5 & Over Production (O) & $10.81 \%$ & $83.19 \%$ \\
\hline 7 & $\begin{array}{c}\text { Excessive } \\
\text { Transportation (T) } \\
\text { Inappropriate } \\
\text { Processing (P) }\end{array}$ & $9.12 \%$ & $92.33 \%$ \\
\hline \multicolumn{3}{|r|}{} & $7.67 \%$ \\
\hline
\end{tabular}

\section{Presentase Waste Berdasarkan WAM}

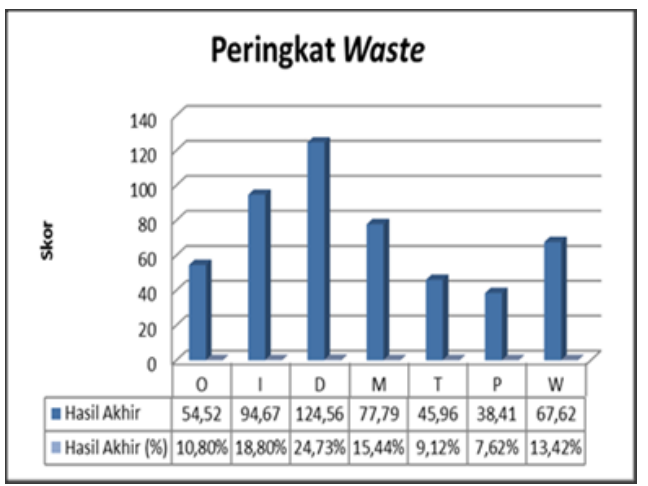

Gambar 6: Presentase waste berdasarkan WAM

Hasil assessmen di atas menunjukkan peringkat pemborosan yang dominan dan sangat berpengaruh terhadap jenis pemborosan lainya, dari hasil tersebut maka perlu diadakan perbaikan agar dapat meminimasi pemborosan di lantai produksi.

\section{Kesimpulan}

Hasil penelitian ini adalah sebagai berikut.

1. Tiga jenis pemborosan yang paling sering terjadi di area produksi pada PT Adi Satria Abadi dengan metode Waste Assessment Model (WAM) adalah Defect/Reject (24,73\%), Inventory (18,80\%), dan Motion (15,44\%).

2. Lead time material di lantai produksi menjadi lebih cepat, pada VSM sebelum 602,205 menit sedangkan lead time VSM usulan adalah 540,03 menit, terdapat pengurangan waktu sekitar $10 \%$.

3. Dari hasil penelitian terdapat peningkatan throughput produksi pada VSM usulan sebesar 77 unit atau sebesar 5.8\%. Dalam waktu siklus 602,25 menit sebelum perbaikan bisa digunakan untuk memproduksi 1.322 pcs sarung tangan, setelah perbaikan bisa memproduksi 1.399 pcs. 


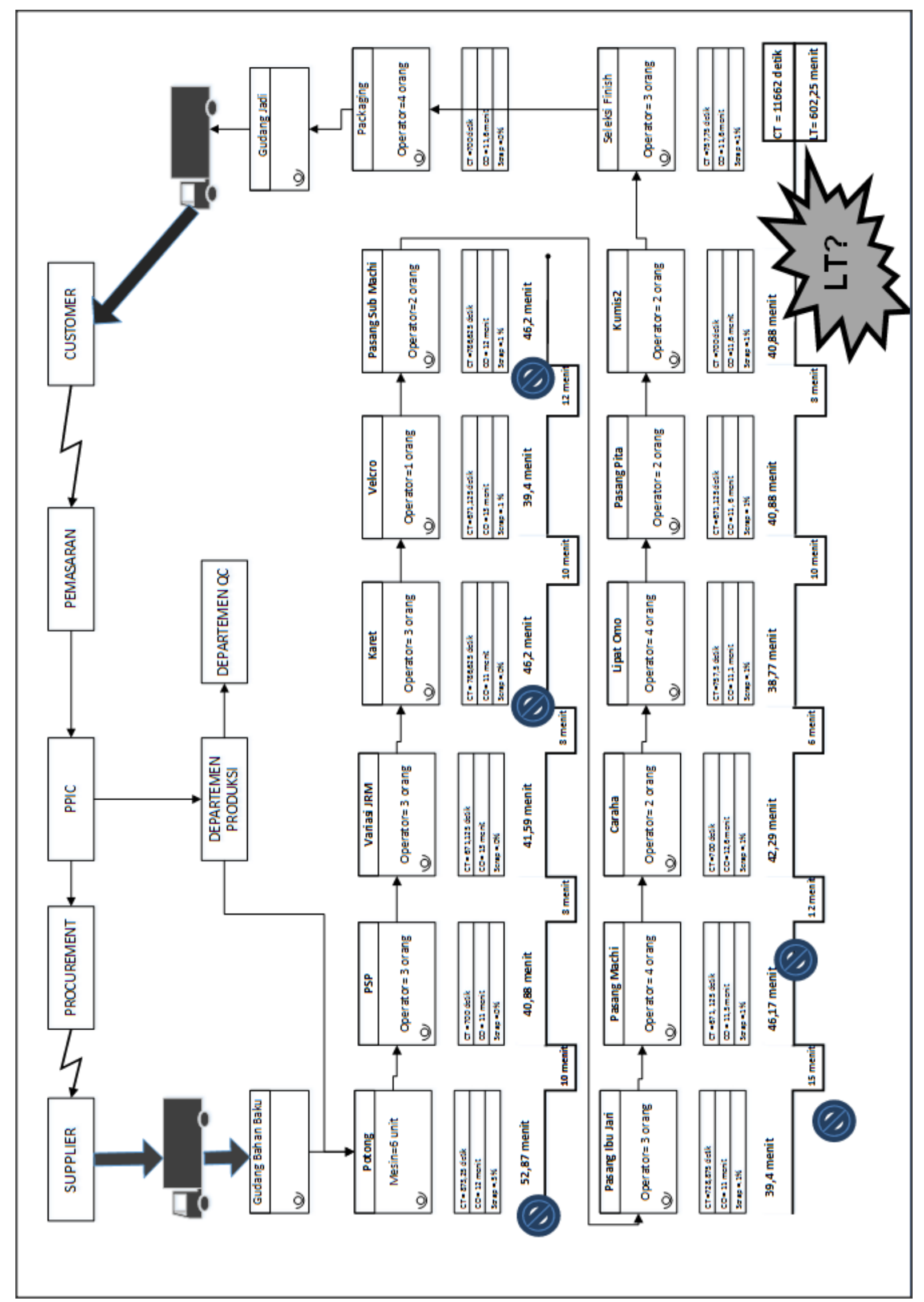

Gambar 7: Value Stream Mapping saat ini (current VSM) 


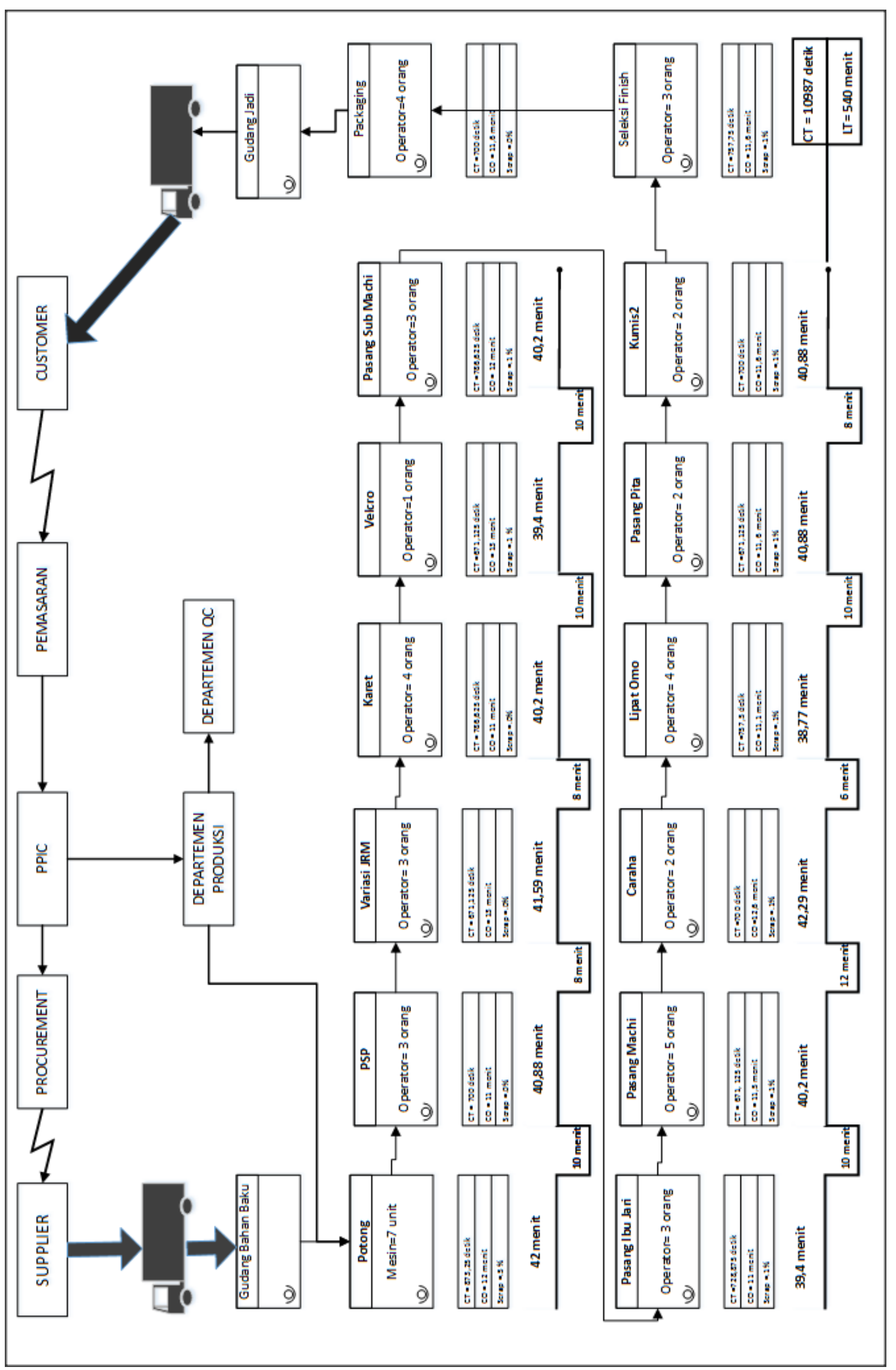

Gambar 8: Value Stream Mapping usulan (proposed VSM) 


\section{Daftar Pustaka}

Chaeron, M., Sentosa, R. (2014). Implementasi Lean Thinking pada Industri Penyamakan Kulit, Prosiding Industrial Engineering Conference (IEC) 2014, UPN Veteran Yogyakarta.

Daonil. (2012).Tesis : Implementasi Lean Manufacturing Untuk Eliminasi Waste Pada Lini Produksi Machining Cast Wheel Dengan Menggunakan Metode Wam Dan Valsat, Tahun 2012, Depok:Fakultas Teknik Program Studi Teknik Industri Universitas Indonesia.

Fontana, Avanti , Gaspers, V., (2011). Lean Six Sigma For Manufacturing and Service Industries. Bogor : Vinchristo Publication.

Gaspersz, Vincent. (2007). Lean Six Sigma For Manufacturing and Service Industries. Jakarta : Gramedia Pustaka Utama.

Muzakki, Misbahul. (2012). Skripsi: Perancangan Sistem Produksi Untuk Mencapai Kondisi Lean Manufacturing Menggunakan Value Stream Mapping pada Sektor Industri Susu Balita Tahun 2012, Depok: Fakultas Teknik Universitas Indonesia

Pertiwi, Kusuma. (2012). Skripsi : Lean Hospital Sebagai Usulan Perbaikan Sistem Rack addressing dan Order Picking Gudang Logistik Perbekalan Kesehatan Rumah Sakit Islam Jakarta Cempaka Tahun 2012, Depok: Fakultas Kesehatan Masyarakat Universitas Indonesia

Rawabdeh, I.A. (2005). A model for the assessment of waste in job shop environments, International Journal of Operations \& Production Management. Vol.25 issue 8 .

Sandroto, I.V, Kurniadi. (2007). Value Stream Mapping, Proceeding International Seminar on Industrial Engineering and Management, ISSN: 1978-774X 